DOI: $10.17058 /$ redes.v20i3.4745

\title{
EFICIÊNCIA DO GASTO PÚBLICO NA FORMAÇÃO DO CAPITAL HUMANO
}

\section{EFFICIENCY OF PUBLIC SPENDING RELATED TO HUMAN CAPITAL FORMATION}

\author{
Martin Airton Wissmann \\ Universidade Estadual do Oeste do Paraná - Toledo - PR - Brasil
}

\begin{abstract}
Resumo: O objetivo deste estudo é apurar a eficiência do gasto público com o Ensino Fundamental - séries iniciais, frente à formação de Capital Humano, na região Oeste do Paraná, a partir da evolução do Índice de Desenvolvimento da Educação BásicaIDEB, bem como analisar as possíveis variáveis que podem impactar nos resultados deste índice. Tem-se, a partir da teoria do Capital Humano, que a educação pode interferir de forma determinante no futuro de uma pessoa, sobretudo quando apresenta qualidade nas séries iniciais. Nesse contexto, partindo da premissa que o IDEB é o indicador de qualidade do ensino, portanto, de formação de Capital Humano, e que este pode ser influenciado pelos investimentos realizados pelo poder público, analisou-se os gastos com Ensino Fundamental - séries iniciais, realizados pelos municípios do Oeste do Paraná, no período de 2006 a 2011 e comparou-se com os resultados do IDEB. Os resultados demonstraram que a evolução nos resultados do IDEB foi proporcionalmente menor que o crescimento dos gastos com educação, denotando falhas na formação de Capital Humano. Identificou-se, também, que dentre as variáveis que exercem maior influência na dimensão Avaliação, a variável Meta 3 é a que deve receber maior atenção na definição de intervenções e de formulação de políticas públicas voltadas à educação.
\end{abstract}

Palavras-chave: Capital Humano. Eficiência. Educação.

Abstract: This paper analyzes efficiency of public spending related to human capital formation in basic primary school in the East Paraná region. As data served the IDEB index and an analyze of its variables that might have impacted those results. The theory of human capital concludes that education can interfere essentially in the development of a person, especially due to excellence in instruction for the initial years. Based on this concept and that the IDEB índex is appropriate to measure quality of instruction and, consequently of human capital, the research supposes that public spending influences the IDEB index. Thus, the research determined the spending on basic primary school, carried out by the municipalities of the East Paraná region between 2006 and 2011 and compared them with the results of the IDEB index. The results reveal that the development of the IDEB index was proportionately lower than 
the increase of public spending, indicating possible failure in formation of human capital. It also exhibits that between the variables that influences the dimension evaluation, the variable Meta 3 is the one that should demand more attention related to interventions and public policies in education.

Keywords: Human capital. Efficiency. Education.

\section{INTRODUÇÃO}

A evolução do conhecimento sempre foi fonte de estudo e instiga pela possibilidade de interferir no futuro das pessoas. Essa interferência, normalmente positiva, fez surgir a teoria do Capital Humano que, conforme apresentam diversas publicações, foi difundida a partir da década de 1960 por Theodore William Schultz.

Conforme preconiza Schultz (1987), para que um país apresente desenvolvimento deverá promover investimentos, em grande proporção, em recursos humanos, tomando o cuidado de não os promover, exclusivamente, em capital fixo. As vantagens tecnológicas só são plenamente aproveitadas se houver significativo desenvolvimento de Capital Humano. Complementa dizendo que, embora não seja o único fator, é importante que um país invista primeiro em Capital Humano o que refletirá, invariavelmente, em desenvolvimento econômico, e que as instituições escolares têm papel fundamental na formação desse capital (SCHULTZ, 1967 e 1973).

Seguindo o entendimento da teoria do Capital Humano frente à necessidade de investimentos em educação, Heckman (2000) destacou que intervenções na educação já nas fases iniciais do processo educativo reduzem a vulnerabilidade das crianças e aumentam a produtividade destas, quando entrarem no mercado de trabalho. Essa afirmativa é confirmada nos estudos de Cunha et al. (2005), os quais demonstraram que investimentos em Capital Humano apresentam diferenças significativas de acordo com o momento em que ele ocorre. A taxa de retorno na Educação Infantil é maior do que o retorno observado quando esse investimento ocorre em idades mais avançadas, ou seja, investimentos maiores e mais adequados nos primeiros anos de ensino trazem maior retorno na formação do Capital Humano.

Com base nessa sustentação teórica, a presente pesquisa foi desenvolvida tendo como objeto de estudo os municípios da região Oeste do Paraná, e está pautada no fato de não haver parâmetro que 
possa avaliar se os gastos com educação desses municípios estão surtindo os efeitos desejados na qualidade do ensino, representados pelo resultado do IDEB. Complementar a isso, entende-se que independente do resultado, olhando pelo aspecto da qualidade, sempre haverá possibilidades de melhoria, portanto, surge da mesma forma um questionamento sobre quais variáveis devem ser levadas em consideração na definição de políticas públicas ou de intervenção visando à melhoria nos resultados do IDEB, por consequência, na formação de Capital Humano para a região.

Dessa forma, tem-se como objetivo apurar a eficiência dos gastos públicos com o Ensino Fundamental - séries iniciais, frente à formação de Capital Humano, na região Oeste do Paraná, a partir da evolução do IDEB de 2005 para 2011, além de analisar as possíveis variáveis que podem impactar nos resultados deste índice.

Nesse contexto, entende-se que a presente pesquisa pode, em primeiro lugar, demonstrar o grau de eficiência na formação de Capital Humano pelos municípios da região Oeste do Paraná, refletidos na evolução do IDEB, e, em segundo lugar, apontar variáveis que devem ser utilizadas como parâmetro para definição de intervenções ou elaboração de políticas públicas voltadas para educação básica.

\section{REFERENCIAL TEÓRICO}

\subsection{Breve Abordagem da Origem do Capital Humano}

No intuito de promover uma breve abordagem da origem do Capital Humano, considera-se importante destacar que, conforme menciona Medeiros (1982), a expressão Capital Humano, embora pareça estranha, tem a intenção de simplesmente destacar os atributos do ser humano, caracterizando as qualidades da mão de obra. Há inúmeros fatores que intervém quando o ser humano decide aumentar sua escolaridade. A possibilidade de maiores ganhos sempre foi levada em consideração pelo homem que vive em uma economia de mercado. Com base nisso, os defensores do Capital Humano procuraram explicitar o papel da educação formal e de outros atributos individuais na obtenção de maiores ganhos. Destaca-se que a escolaridade é um modelo onde se podem identificar os percentuais de incrementos de ganhos dos 
indivíduos com base na proporção de tempo despendido na escola. (MEDEIROS, 1982).

Diante da intenção de explicitar esse atributo, incrementado pela escolaridade, desenvolveu-se a teoria do Capital Humano, a qual, conforme Siedenberg (2012), surgiu dos estudos de Theodore William Schultz, que, ao observar a rápida recuperação da Alemanha e do Japão no pós-guerra, identificou que esta estava associada com as boas condições de saúde (alimentação) e alto nível de educação da população. Frente aos resultados observados, Schultz desenvolveu a teoria do Capital Humano como elemento crucial para o desenvolvimento socioeconômico de países, defendendo que os investimentos em educação, treinamento e desenvolvimento de conhecimentos e habilidades têm relação direta com o aumento da produtividade, da lucratividade e aumento da renda dos trabalhadores.

Ao discorrer buscando a difusão da teoria, Schultz (1987) abordou que o desenvolvimento de um país não dependerá exclusivamente, ou em maior proporção, dos investimentos em capital fixo e, sim, em grande proporção, dos investimentos em recursos humanos realizados pelos setores públicos e privados. As vantagens tecnológicas só são plenamente aproveitadas se houver significativo desenvolvimento de Capital Humano.

Em um estudo de Saul (2004), o autor apresenta o contexto e diferentes pensadores que abordaram o Capital Humano em suas pesquisas. Menciona que, embora Theodore Schultz tenha anunciado o surgimento da teoria em 1960, esta ganhou notoriedade a partir de 1962 pela revista científica americana Journal of Political Economy, e que Mark Blaug, em seus estudos publicados em 1986, teria encontrado fontes primárias da teoria em importantes autores como Adam Smith, Alfred Marshall e Irving Fisher, este último teria adotado a teoria do capital de Walras, entendendo por capital o conjunto de riquezas existentes em um determinado tempo, os quais possibilitam o fluxo de serviços, sendo a terra, as máquinas, a matéria-prima, os recursos naturais e as qualidades do homem.

Os pesquisadores Lars Nedrum e Truls Erikson, em estudo publicado em 2001, acrescentam que William Petty teria sido o primeiro economista a destacar as diferenças de qualidade do trabalho e o que, mais tarde, seria conhecido como Capital Humano. Os autores também 
sustentam que a noção de capital de Fisher é a fonte primária da teoria moderna do Capital Humano, na forma em que ele surgiu em 1950. Jacob Mincer e Theodore Schultz, partindo de Fisher, passaram a considerar o Capital Humano como um capital independente do convencional em relação às características econômicas e produtivas de um país. (SAUL, 2004).

Dentre os diversos estudos desenvolvidos com base neste tema, a menção a Theodore Wiliam Schultz como o principal precursor é recorrente, e muito se deve a duas das principais publicações do autor: O Capital Humano e O Valor Econômico da Educação. Ao fundamentar a discussão sobre a teoria do Capital Humano e sua formação, Schultz destaca, nessas obras, que é necessário que um país invista primeiro em Capital Humano para que, depois, haja desenvolvimento econômico e que a principal função das instituições escolares é a pesquisa, descobrir e estimular os talentos dos alunos e instruir para que estes saibam lidar com as oportunidades, ou seja, a educação e o progresso no conhecimento constituem importantes fontes de evolução econômica. (SCHULTZ, 1967 e 1973).

Independente de sua origem e de seu maior ou principal precursor, o fato certo é que a teoria do Capital Humano é fonte de sustentação para vários estudos e análises, visto que destaca a importância da formação humana e que esta resultará em crescimento/desenvolvimento econômico.

\subsection{Reflexos e Importância do Capital Humano}

O crescimento de um país, de um estado, de uma região ou município está vinculado a uma série de fatores, os quais exercem maior ou menor influência.

Para Viana e Lima (2010), os estudos clássicos da economia determinam que o crescimento econômico esteja vinculado aos fatores de produção terra, capital e trabalho. Este último, composto por faculdades físicas e intelectuais dos seres humanos, os quais são elementos básicos para produção de bens e serviços que gerarão riquezas e influenciarão o desempenho econômico.

Há um reconhecimento que as mudanças estruturais, ocorridas nas economias mais desenvolvidas, reduziram a importância dos 
tangíveis e aumentaram a importância dos ativos intelectuais ou do conhecimento. Nesse contexto, a economia é influenciada por setores ou atividades com alta dotação de conhecimento, crescendo a importância do capital intelectual, ou seja, do capital intangível. (DINIZ; GONÇALVES, 2005).

De acordo com Haddad (2009), há um contexto com novas concepções buscando explicar a razão pela qual alguns países e regiões se desenvolvem mais rapidamente que os demais. As novas concepções ressaltam o conhecimento como um fator de produção ao qual se deve atribuir importância por meio de investimentos na criação do conhecimento e nas atividades de pesquisa e desenvolvimento. Ressalta que o Capital Humano, entre outros fatores, determina o crescimento econômico em longo prazo, possibilitando transformá-lo em processos de desenvolvimento de um país ou região.

Ao relacionar o nível de instrução com o crescimento econômico, Berchielli (2000) destaca que o segundo está quase sempre associado à existência de uma população com maior nível de instrução, ou seja, uma população melhor capacitada para explorar e adotar inovações tecnológicas e de mercado, com isso tende a propiciar, aos seus membros, condições eficazes para o aproveitamento dos benefícios do desenvolvimento.

De acordo com Schultz (1973), o Capital Humano é um termo utilizado para designar as aptidões e habilidades dos indivíduos, as quais resultam em geração de renda. Becker (1983) complementa que este é fundamentalmente dependente do sistema educacional.

O investimento em Capital Humano propiciará aumento da produtividade e, como consequência, também tenderá a trazer melhoria na distribuição de renda no longo prazo. Aumentar investimentos em educação, normalmente, também representará aumento de investimentos na saúde e nutrição, resultando em maior desempenho socioeconômico do país. Dessa forma, as ações que elevam os investimentos em Capital Humano tornam-se inquestionáveis, pois elevam o padrão de vida da comunidade. (BERCHIELLI, 2000).

Ocorre que no ambiente privado, no caso as empresas, os investimentos visando à formação do Capital Humano normalmente atendem interesses restritos, tornando os investimentos limitados ao objetivo imediato. "Como as empresas tendem a subinvestir em P\&D, 
onde os resultados são apenas parcialmente capturados e apropriados por elas, os governos nacionais e regionais deveriam tomar medidas apropriadas para superar esta falha de mercado." (HADDAD, 2009, p.120).

Nesse contexto, surge a importância e necessidade do poder público investir na educação, em todos os níveis, pois tenderá a refletir em resultados futuros que beneficiarão o país como um todo. Para Berchielli (2000), as políticas de desenvolvimento voltadas para estrutura de longo prazo encontram nos investimentos em Capital Humano um facilitador do processo de ajustamento econômico, pois esses investimentos melhoram a qualidade dos seres humanos e, também, os níveis de produção, emprego e renda, que passam a se adaptar melhor à economia internacional e a promover o crescimento sustentado no país.

Com base na afirmação de Haddad, derivada de estudos relacionados a ativos intangíveis e seus reflexos no desenvolvimento regional, e de Berchielli, defendendo a importância de políticas públicas que visam à promoção do Capital Humano, este estudo parte da premissa que a educação básica, antes mesmo que o indivíduo ingresse no mercado de trabalho e possa ser incluído em programas de treinamento das empresas, é a sustentação do futuro desenvolvimento econômico e social de uma região, entendendo que este estágio fundamental é obrigação dos municípios, conforme preconiza a lei.

De acordo com Reis (2012), o caminho para uma criança ter um bom aproveitamento na escola para, depois, ter a possibilidade de ingressar na faculdade e conquistar um bom emprego é resultado de um adequado investimento no primeiro ciclo do Ensino Fundamental, que vai do primeiro ao quinto ano (primeira à quarta série, antes da implantação do Ensino Fundamental de nove anos). Essa afirmação está apoiada em um estudo desenvolvido pelo Instituto de Ensino e Pesquisa-Insper - SP, de 2011, onde constatou-se que o bom aproveitamento da criança nessa fase é decisivo para que ela tenha um excelente desempenho na universidade e, consequentemente, esteja melhor preparada para enfrentar o mercado de trabalho.

Segundo a autora, o estudo também identificou que os estados brasileiros com os melhores índices de avaliação do Ensino Fundamental - regiões Sul e Sudeste - apresentam instituições de ensino superior 
com mais qualidade. Além disso, essa pesquisa concluiu que quanto antes a criança ingressar na escola, maiores serão as chances de ela ter sucesso na vida.

Dessa forma, pode-se inferir que o ensino reforça a teoria do Capital Humano, no que diz respeito à força de trabalho e sua renda. Por outro lado, destaca a importância da qualidade do ensino desde a educação básica, logo nas séries iniciais. 


\subsection{A Importância do Investimento em Educação para Formação do Capital Humano}

Investimento no fator humano é determinante para o aumento da produtividade, constituindo-se como fator explicativo das diferenças individuais de produtividade e renda. (FRIGOTTO, 1993). Aqueles com baixo conteúdo de Capital Humano têm baixa produtividade e, por esse motivo, tendem a serem pessoas mal sucedidas economicamente, em comparação com os indivíduos de alto conteúdo de Capital Humano. (BERCHIELLI, 2000).

Ao ressaltar a importância do investimento no fator humano, Berchielli (2000) destaca que o melhor desempenho no futuro dependerá de uma escolaridade ampla, além de boa saúde e adequada nutrição. Dessa combinação, sobretudo com uma escolaridade adequada, tem-se como resultado o aumento da produtividade da força de trabalho, menor pressão demográfica, renda per capita maior, entre outros. Para atingir esses resultados, é preferível que se tenha uma boa alfabetização e uma educação básica forte para depois aumentar os investimentos na formação secundária e superior.

Heckman (2000), ao abordar a importância dos investimentos na educação, destacou que a origem de muitos problemas sociais e econômicos estão relacionados ao baixo nível de ensino e, portanto, intervenções na educação já nas fases inicias do processo educativo reduzem a vulnerabilidade das crianças e aumenta a produtividade destas quando entrarem no mercado de trabalho.

De acordo com Cunha et al. (2005), investimentos em Capital Humano apresentam diferença significativa de acordo com o momento em que ele ocorre. Conforme demonstra a Figura 1, a taxa de retorno na Educação Infantil é maior do que o retorno observado quando esse investimento ocorre em idades mais avançadas. O investimento ideal está representado no gráfico pela letra $r$, custo de oportunidade, ou seja, momento em que iguala a taxa marginal de retorno. Portanto, é possível entender que investimentos maiores e mais adequados nos primeiros anos de educação trazem maior retorno na formação Capital Humano. 


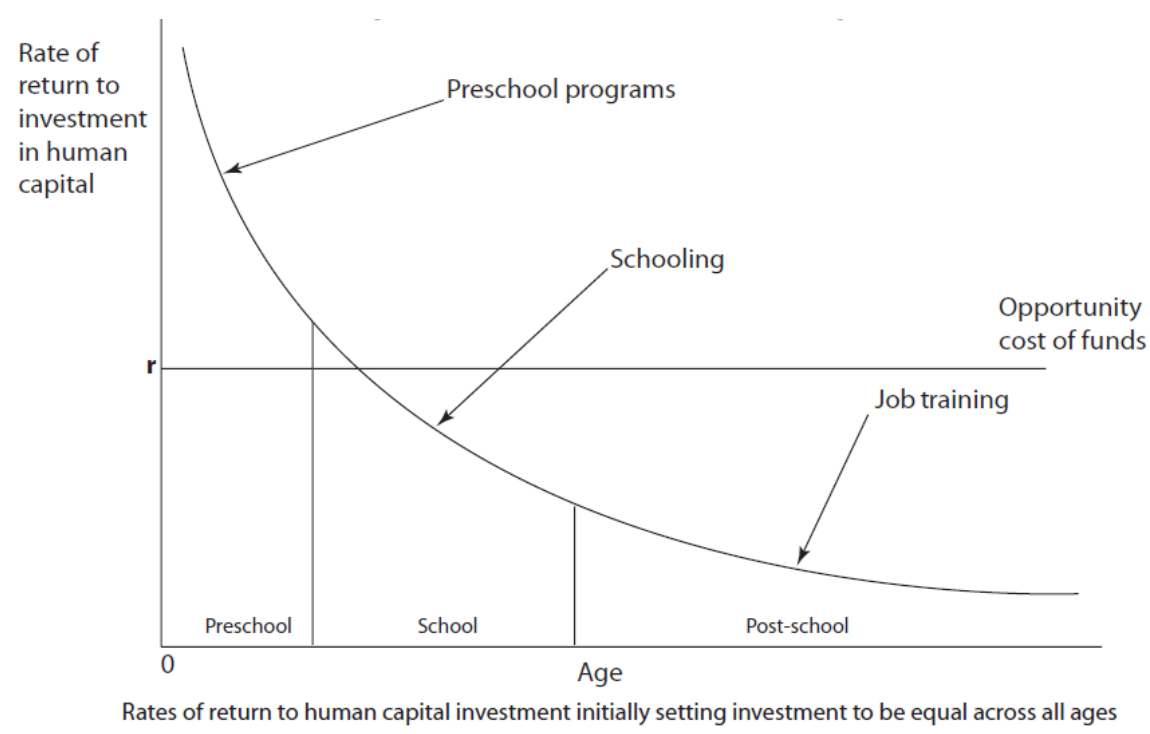

Figura 1. As taxas de retorno de investimento em Capital Humano.

Fonte: Cunha et al. (2005, p. 112).

Neri (2005), ao se referir ao estudo desenvolvido por James J. Heckman e Flávio Cunha, menciona que os resultados demonstraram que as crianças que tiveram a oportunidade de frequentar o ambiente educacional desde a pré-escola apresentaram, na idade adulta, renda mais alta e probabilidades mais baixas de prisão, de gravidez precoce e de depender de programas de transferência de renda do Estado no futuro. O que resultou na conclusão de que é mais produtivo, do ponto de vista social e fiscal, investir na educação das crianças desde a primeira infância, e que quanto mais investimento, melhores os reflexos, constituindo-se num verdadeiro custo de oportunidade social.

Considerando que a educação na alfabetização e nos anos iniciais do ensino fundamental, no Brasil, é obrigação dos municípios, Berchielli (2000) demonstrou certa preocupação ao mencionar que os investimentos em Capital Humano são sensíveis à qualidade dos serviços públicos os quais variam bastante, muitas vezes, ficando abaixo do ideal. Destaca que poderiam ser alcançados resultados melhores na educação básica e ao mesmo tempo obter altas taxas de retorno no Capital Humano se fosse adotadas medidas simples, como aumentar a disponibilidade de livros didáticos e de material escolar nos níveis iniciais de escolaridade e treinamento dos profissionais da educação.

O autor complementa que a escola pública no Brasil é um problema crônico, tendo se transformado em um agente monopolista de ensino básico, atendendo, sobretudo, a classe pobre e oferecendo um 
serviço de baixa qualidade, ou seja, nesse contexto, dificilmente conseguirá obter eficiência e alta qualidade.

Para avaliar a qualidade do ensino no Brasil, criaram-se alguns índices a partir da medição de resultados frente à aplicação de avaliações, apuração de evasão escolar e taxa de reprovação nos diversos níveis educacionais existentes no país. Dentre eles destacamse o Exame Nacional de Desempenho de Estudantes- ENADE1 e o IDEB.

Visando a atender os objetivos deste estudo, destaca-se o IDEB, que, de acordo com Costa (2010), trata-se do principal indicador de qualidade da educação básica no Brasil, sendo aferido e divulgado pelo Ministério da Educação-MEC por intermédio do Instituto Nacional de Estudos e Pesquisas Educacionais Anísio Teixeira-INEP, a cada dois anos.

De acordo com o INEP (2013a), o IDEB foi criado em 2007 no intuito de reunir, num só indicador, dois conceitos igualmente importantes para a qualidade da educação: Fluxo Escolar e Médias de Desempenho nas Avaliações. É possível inferir que, considerando que o fluxo escolar refere-se à aprovação ou retenção dos alunos, se a escola retiver alunos pensando em selecionar os que farão as avaliações, refletirá negativamente no fluxo, ao contrário, com aprovação sem critério, poderá refletir negativamente no resultado das avaliações, portanto, deve haver resultados conjuntamente positivos a fim de alcançar um bom resultado no IDEB.

Portanto, o IDEB é calculado a partir dos dados sobre aprovação escolar, obtidos no Censo Escolar e por meio das médias de desempenho nas avaliações do Inep o Sistema Nacional de Avaliação da Educação Básica - SAEB -, para as unidades da federação e para o país, e a Prova Brasil - para os municípios. Portanto, o indicador agrega ao enfoque pedagógico dos resultados das avaliações em larga escala do INEP a possibilidade de resultados sintéticos, que permitem traçar metas de qualidade educacional. (INEP, 2013a).

Numa visão mais abrangente e de comprometimento com os resultados, o IDEB é um indicador que combina informações de Fluxo Escolar e da Avaliação dos alunos, criado para promover um sistema de 
responsabilidade', visando à melhoria da qualidade da educação no país. (COSTA, 2010).

Em relação à responsabilidade, tem-se, conforme preconiza a Lei n 9.394/96 (Lei de Diretrizes e Base da Educação - LDB ), em seu artigo $4^{\circ}$, que é dever do Estado disponibilizar Ensino Fundamental, obrigatório e gratuito, inclusive para os que a ele não tiveram acesso na idade própria, com progressiva extensão de obrigatoriedade e gratuidade ao ensino médio, atendimento ao educando, no Ensino Fundamental público, por meio de programas suplementares de material didático-escolar, transporte, alimentação e assistência à saúde, além de garantir padrões mínimos de qualidade de ensino definido como a variedade e quantidade mínimas, por aluno, de insumos indispensáveis ao desenvolvimento do processo de ensinoaprendizagem.

A mesma lei, em seu artigo 11, determina enquanto incumbência dos municípios, oferecerem a Educação Infantil, com prioridade ao Ensino Fundamental, permitida a atuação em outros níveis de ensino somente quando estiverem atendidas plenamente as necessidades de sua área de competência e com recursos acima dos percentuais mínimos vinculados pela Constituição Federal à manutenção e desenvolvimento do ensino.

Para efetivo cumprimento de sua responsabilidade frente à educação gratuita, os municípios, conforme prevê a Constituição Federal-CF (1988), em seu artigo 212 , deverão aplicar, no mínimo, vinte e cinco por cento da receita resultante de impostos, compreendida a proveniente de transferências, na manutenção e desenvolvimento do ensino.

Dessa forma, é possível inferir, conforme embasamento teórico, que o processo educacional ofertado pelos estabelecimentos de ensino é o fundamental formador de Capital Humano, que, quando bem desenvolvido nos primeiros anos escolares, trará reflexos no futuro, resultando positivamente no crescimento econômico de um país e possibilitando ao indivíduo uma melhor renda. Portanto, conforme a

\footnotetext{
1 A expressão responsabilidade deve ser entendida, neste contexto, como tradução literal do vernáculo inglês accountability, designando a obrigação dos agentes públicos em responder por suas decisões, ações e omissões, procedimento universalmente consagrado como norma nas sociedades mais desenvolvidas.
} 
teoria do Capital Humano, quanto maior o acesso a educação de qualidade, melhores os resultados futuros dos indivíduos. Por outro lado, embora as obrigações públicas com a oferta do ensino gratuito são definidas pela legislação, há poucos estudos científicos e/ou indicadores governamentais que mensuram a qualidade do gasto público com o ensino e, por consequência, com a formação de Capital Humano. 


\section{METODOLOGIA}

Os procedimentos metodológicos foram utilizados de forma a desenvolver duas etapas de coletas de dados e, consequentemente, duas etapas de análises, sendo a primeira composta dos gastos dos municípios, objeto de estudo, com a educação básica e seus respectivos resultados no IDEB e a segunda, resultante da identificação da dimensão que mais impacta neste índice - Fluxo Escolar ou Avaliação, e as variáveis que podem influenciá-la.

Utilizou-se como fonte de dados para a primeira parte das análises, os gastos públicos com o Ensino Fundamental - séries iniciais, dos municípios que compõem a Região Oeste do Estado do Paraná, ilustrados na figura 2. Desses municípios, foram excluídos Catanduvas, que no IDEB 2011 teve número de participantes na Prova Brasil insuficiente para que os resultados fossem divulgados, e o Município de Serranópolis do Iguaçu, que não apresentou média na Prova Brasil 2011, resultando em 48 municípios analisados.

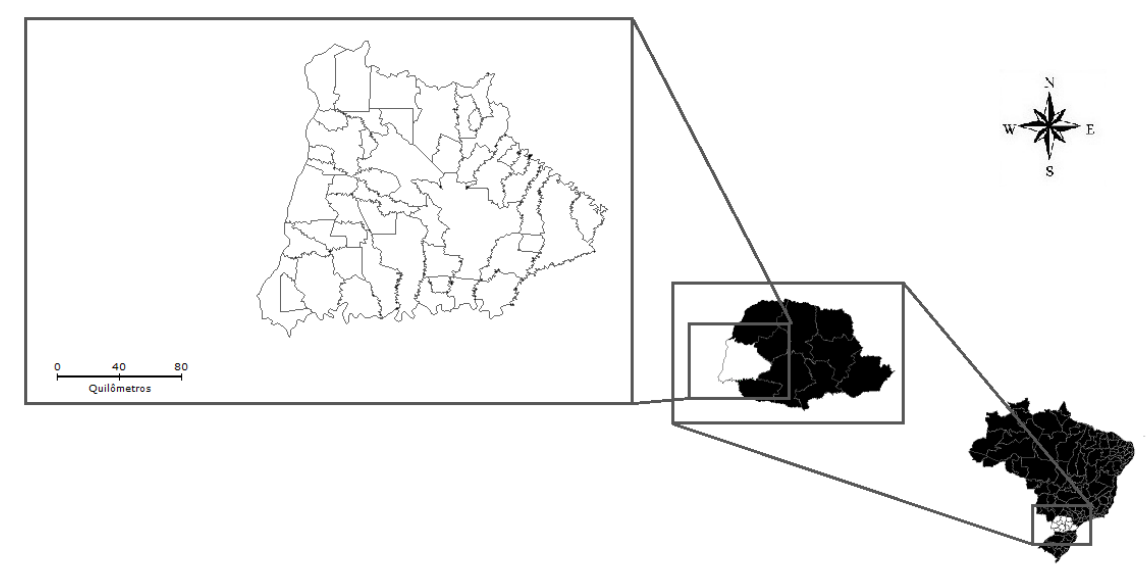

FIGURA 2. Região Oeste do Paraná - Brasil.

Fonte: Elaborado pelo autor.

Os gastos foram coletados a partir do Quadro de Dados Contábeis Consolidados Municipais do Balanço Orçamentário - Despesas por Função (função 12), que, de acordo com MOG - Portaria $n^{\circ} 42 / 99$, refere-se ao conjunto de ações governamentais voltadas à formação intelectual, moral, social, cívica e profissional do indivíduo, preparandoo para o exercício consciente da cidadania, e habilitando-o para uma participação eficaz no processo de desenvolvimento econômico e social. 
Considerando que a função 12 engloba todos os gastos com educação, incluindo os demais níveis de ensino, para atender os objetivos deste estudo, utilizou-se somente os valores que compõem a subfunção 361 - Ensino Fundamental, a qual é composta por todos os gastos destinados às ações que visam proporcionar ensino e formação a crianças e pré-adolescentes, no caso dos municípios brasileiros, os gastos destinados ao Ensino Fundamental - séries iniciais.

Os gastos utilizados referem-se ao período de 2005 a 2011, sendo que a base de comparação refere-se a 2005, ano da divulgação do primeiro IDEB, o qual teve três aferições a partir do ano base, sendo 2007, 2009 e 2011 . Entende-se que os gastos podem trazer reflexos em mais de um ano, não necessariamente somente no período em que foram aplicados, ou seja, gastos realizados em 2006 e 2007 podem ter trazido reflexos no IDEB de 2007, e assim sucessivamente até 2011.

Visando dar tratamento igualitário nas análises, independente de tamanho do município, optou-se primeiro em corrigir os valores dos gastos com educação para 2011, com base no Índice Nominal de Preços ao Consumidor Amplo-IPCA, para depois identificar o gasto por aluno matriculado (per capita).

A análise da confrontação entre Gasto com Educação e IDEB se deu a partir dos dados financeiros corrigidos, identificando a evolução dos gastos do período 2006 a 201 1, em relação a 2005, e do IDEB 2007 a 2011 , em relação a 2005. Destaca-se que a fonte de onde foram obtidos dados é: Gastos com Educação do Sistema de Coleta de Dados Contábeis de Estados e Municípios-SISTN (2013), disponibilizados pelo Tesouro Nacional; resultados do IDEB, $4^{\mathrm{a}}$ série $/ 5^{\circ}$ ano foram coletados a partir do IDEB - Resultados e Metas, disponibilizado pelo INEP (2013b); e das matrículas, a partir do Sistema de Consulta a Matrícula do Censo Escolar, INEP (2013c).

Após a análise dos dados, a partir da confrontação dos gastos com educação frente ao IDEB, observou-se que os resultados por si só já permitiam emitir conclusões a respeito, porém, sabe-se que outros fatores podem interferir nesse resultado, o que gerou a necessidade de aplicar um método que pudesse avaliar a eficiência do gasto. Para obter esse resultado, utilizou-se um método amplamente difundido no meio acadêmico e que pode retratar com qualidade os resultados, conhecido como Data Envelopment Analysis-DEA. É um método matemático que utiliza a programação linear para estimar a fronteira eficiente. 
Análise Envoltória de Dados-DEA, conforme descrevem Gomes e Mangabeira (2004), é um método matemático apoiado na programação linear, utilizado para estimar a fronteira eficiente, entre os inputs (entradas, recursos, insumos ou fatores de produção) e outputs (saídas ou produtos) para o cálculo da eficiência de unidades tomadoras de decisão, designadas por Decision Making Units - (DMU's).

Em relação a sua aplicação a partir de recursos públicos, Delgado e Machado (2007) defendem que a DEA pode ser útil para a análise da eficiência no âmbito público, pois é capaz de captar a melhor prática existente da organização e cria um referencial para as instituições analisadas.

No estudo, utilizou-se como input o Gasto Médio Per capita entre 2006-2011, no Ensino Fundamental - séries iniciais, e como output a Evolução do IDEB 2011 em relação a 2005 (\%) dos 48 municípios objetos de estudo.

No intuito de ampliar as análises frente aos resultados observados a partir da aplicação da DEA, ou seja, após identificar os municípios mais ou menos eficientes na aplicação dos recursos públicos para educação, utilizou-se a Regressão Múltipla de forma a apurar qual das duas dimensões que compõe o IDEB: Fluxo Escolar e Avaliação têm maior impacto na sua composição. Para tanto, utilizou-se a seguinte fórmula:

$$
Y=b_{0}+b_{1} X_{1}+b_{2} X_{2}+\varepsilon
$$


Em que,

$Y$ - Variável dependente IDEB;

$X_{1}$-Variável independente Fluxo Escolar;

$X_{2}$ - Variável independente Avaliação;

$\varepsilon$ - Erro.

Após a identificação da dimensão mais representativa ou explicativa para os resultados do IDEB, levantou-se sete variáveis, escolhidas por apresentarem possíveis influências na dimensão Avaliação, aplicando-se novamente a Regressão Múltipla, de forma a apurar qual variável causa maior impacto, portanto, podendo definir possíveis intervenções ou definições de maiores investimentos. Para tanto, utilizou-se a seguinte fórmula:

$$
Y=b_{0}+b_{1} X_{1}+b_{2} X_{2}+b_{3} X_{3}+b_{4} X_{4}+b_{5} X_{5}+b_{6} X_{6}+b_{7} X_{7}+\varepsilon
$$

Em que,

$Y$ - Variável dependente Avaliação;

$X_{1}$-Variável independente Defasagem idade série - \% de 6 a 14 anos sem atraso;

$X_{2}$ - Variável independente Taxa de abandono;

$X_{3}$ - Variável independente Atendimento -\% de 6 a 14 anos na escola;

$X_{4}$ - Variável independente Meta 3 - Todo aluno com aprendizado adequado ao seu ano;

$X_{5}$ - Variável independente Número de pessoas com superior completo;

$X_{6}$ - Variável independente Média de alunos por turma;

$X_{7}$ - Variável independente Média de horas-aula diária;

$\varepsilon-$ Erro.

\section{RESULTADOS E DISCUSSÕES}

Partindo do entendimento teórico sobre a formação do Capital Humano e da importância da educação nesta formação, o estudo foi dividido em duas partes, ambas desenvolvidas com base em dados secundários dos municípios da Região Oeste do Paraná. A primeira parte é composta da análise da evolução do gasto público com educação, em relação aos resultados do IDEB, e a segunda parte, baseia-se na utilização de variáveis visando identificar as que podem refletir nos resultados deste índice. 
É importante mencionar que há o entendimento no que se refere aos diversos fatores e/ou variáveis que podem influenciar a formação de Capital Humano e os resultados do IDEB, porém, para este estudo, optou-se por delimitar os dados analisados, sendo que outros podem servir de base para compor uma nova agenda de pesquisa.

\subsection{Evolução dos Gastos Públicos com Educação versus IDEB}

A primeira análise está apoiada nos estudos de Heckman (2000) que destacam a necessidade de intervenções na educação já nas fases iniciais do processo educativo, o que reduz a vulnerabilidade das crianças e aumenta a produtividade dessas, quando entrarem no mercado de trabalho. $O$ autor destaca, também, que a educação na infância constitui, provavelmente, o melhor investimento social existente e quanto antes houver o investimento educacional, maior será o retorno recebido pelo indivíduo e pela sociedade.

Visando reforçar ainda mais o foco das análises, destaca-se o estudo de Cunha et al. (2005), o qual demonstra que investimentos maiores e mais adequados nos primeiros anos de educação trazem maior retorno na formação Capital Humano, o que foi amplamente difundido por Theodore Willian Schulz.

É importante destacar que os investimentos em educação dos municípios brasileiros são destinados, principalmente, para o Ensino Fundamental - séries iniciais, conforme a legislação preconiza.

Após a coleta e análise dos dados, os resultados mostraram que os gastos com educação, na Região Oeste do Paraná, cresceram em proporção superior ao crescimento do IDEB, conforme demonstra o Gráfico 1. Entre as variáveis comparadas, enquanto os gastos médios per capita (aluno matriculado) de 2006/2007, em relação a 2005, aumentaram 52,7\%, o IDEB aumentou 14,6\%. No período que compreende $2008 / 2009$, houve uma evolução mais equilibrada quando comparado ao período 2006/2007, ou seja, enquanto os gastos per capita aumentaram 12,2\% o IDEB aumentou 9,5\%. A pior evolução ocorreu no período 2010/2011 em relação a 2008/2009, sendo que, enquanto os gastos aumentaram 19,4\%, o IDEB aumentou $2 \%$. 


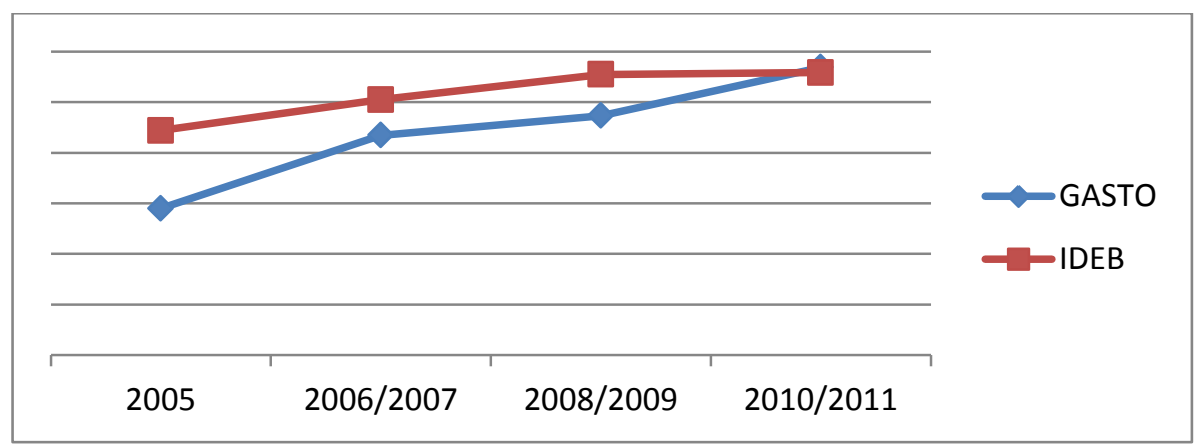

Gráfico 1. Comparativo entre Gasto per capita com o Ensino Fundamental e IDEB.

Fonte: Elaborado pelo autor.

Comparados a 2005, conforme pode ser observado na Tabela 1, a média de gastos per capita no período 2006-2011 teve aumento de $74,51 \%$, enquanto o IDEB apresentou aumento de $27,1 \%$ no mesmo período. Entre os 48 municípios, destaca-se Diamante do Sul, com o pior resultado, pois apresentou um aumento nos gastos médios per capita de 2006 a 2011 em relação a 2005 de 96,27\%, enquanto o IDEB teve comportamento negativo, ou seja, teve queda de $2,3 \%$ no resultado de 2011 em relação a 2005. Como melhor resultado entre os municípios está Santa Helena, que apresentou aumento de 11,3\% nos gastos per capita com o Ensino Fundamental, enquanto o IDEB teve variação positiva de $32,6 \%$. 
Tabela 1. Evolução do Gasto Per capita e do IDEB entre 2005 e 2011

\begin{tabular}{|c|c|c|c|c|c|c|c|c|c|}
\hline MUNICÍPIOS & $\begin{array}{l}\text { GASTO PER } \\
\text { CAPITA } 2005\end{array}$ & $\begin{array}{c}\text { MÉDIA DO } \\
\text { GASTO PER } \\
\text { CAPITA } 2006 \\
\text { A } 2011\end{array}$ & $\begin{array}{c}\text { \% DE EVOLUÇÃO } \\
\text { DO GASTO PER } \\
\text { CAPITA ENTRE } \\
2005 \text { E 2006- } \\
2011 \\
\end{array}$ & $\begin{array}{c}\text { \% EVOLUÇÃO } \\
\text { DO IDEB DE } \\
2005 \text { PARA } \\
2011\end{array}$ & MUNICÍPIOS & $\begin{array}{l}\text { GASTO PER } \\
\text { CAPITA } 2005\end{array}$ & $\begin{array}{c}\text { MÉDIA DO } \\
\text { GASTO PER } \\
\text { CAPITA } 2006 \text { A } \\
2011\end{array}$ & $\begin{array}{c}\text { \% DE EVOLUÇÃO } \\
\text { NO GASTO PER } \\
\text { CAPITA ENTRE } \\
2005 \text { E 2006- } \\
2011 \\
\end{array}$ & $\begin{array}{c}\text { \% EVOLUÇÃO } \\
\text { DO IDEB DE } \\
2005 \text { PARA } \\
2011\end{array}$ \\
\hline Santa T. de Itaipu & $2.001,77$ & $3.420,26$ & 70,86 & 70,5 & Cascavel & $2.134,43$ & $3.447,04$ & 61,5 & 23,4 \\
\hline Foz do Iguaçu & $2.385,57$ & $4.469,20$ & 87,34 & 66,7 & Campo Bonito & $2.956,31$ & $7.389,62$ & 149,96 & 22,7 \\
\hline Guaíra & $2.447,53$ & $3.526,19$ & 44,07 & 61,8 & Braganey & $2.355,51$ & $4.589,85$ & 94,86 & 22,5 \\
\hline Formosa do Oeste & $2.179,12$ & $4.351,15$ & 99,67 & 55,9 & $\begin{array}{l}\text { Entre Rios do } \\
\text { Oeste }\end{array}$ & $3.355,96$ & $6.442,27$ & 91,97 & 22 \\
\hline Iracema do Oeste & $3.177,57$ & $4.964,19$ & 56,23 & 51,3 & Medianeira & $2.187,04$ & $4.293,53$ & 96,32 & 21,7 \\
\hline Nova Aurora & $2.138,20$ & $3.772,59$ & 76,44 & 46,3 & Pato Bragado & $4.068,21$ & $5.580,18$ & 37,17 & 21,7 \\
\hline Matelândia & $2.794,30$ & $4.520,55$ & 61,78 & 43,2 & $\begin{array}{l}\text { Marechal C. } \\
\text { Rondon }\end{array}$ & $2.076,12$ & $3.694,96$ & 77,97 & 19,6 \\
\hline São Pedro Iguaçu & $2.466,11$ & $4.518,57$ & 83,23 & 42,1 & Diamante D'Oeste & $2.930,79$ & $5.181,56$ & 76,8 & 18 \\
\hline Cafelândia & $2.257,59$ & $3.497,31$ & 54,91 & 40,4 & Maripá & $2.765,79$ & $4.836,40$ & 74,86 & 18 \\
\hline Guaraniaçu & $1.947,74$ & $3.486,00$ & 78,98 & 34,8 & Corbélia & $1.948,11$ & $4.633,23$ & 137,83 & 17,8 \\
\hline $\begin{array}{l}\text { Assis } \\
\text { Chateaubriand }\end{array}$ & $2.372,99$ & $4.285,23$ & 80,58 & 33,3 & Missal & $3.272,21$ & $5.528,29$ & 68,95 & 16,3 \\
\hline Iguatu & $3.272,27$ & $6.609,43$ & 101,98 & 33,3 & São Miguel Iguaçu & $3.568,70$ & $5.409,32$ & 51,58 & 15,2 \\
\hline Ouro Verde Oeste & $2.859,01$ & $5.143,97$ & 79,92 & 33,3 & $\begin{array}{l}\text { Capitão L. } \\
\text { Marques }\end{array}$ & $2.407,49$ & $3.807,89$ & 58,17 & 14,3 \\
\hline Toledo & $2.156,47$ & $3.093,27$ & 43,44 & 33,3 & $\begin{array}{l}\text { Boa Vista } \\
\text { Aparecida }\end{array}$ & $1.740,64$ & $3.877,39$ & 122,76 & 14 \\
\hline Santa Helena & $7.851,17$ & $8.738,49$ & 11,3 & 32,6 & Ibema & $2.924,93$ & $5.101,87$ & 74,43 & 13,6 \\
\hline Ramilândia & $2.288,60$ & $4.497,74$ & 96,53 & 31,4 & Santa Lúcia & $3.288,63$ & $4.776,47$ & 45,24 & 13,2 \\
\hline Mercedes & $3.202,37$ & $4.214,47$ & 31,6 & 31,3 & Tupãssi & $3.322,57$ & $4.894,33$ & 47,31 & 12,1 \\
\hline Lindoeste & $2.622,92$ & $4.926,85$ & 87,84 & 30,8 & $\begin{array}{l}\text { São José } \\
\text { Palmeiras }\end{array}$ & $2.797,38$ & $5.308,48$ & 89,77 & 11,9 \\
\hline Nova Santa Rosa & $2.299,09$ & $4.468,06$ & 94,34 & 29,5 & $\begin{array}{l}\text { Santa Tereza } \\
\text { Oeste }\end{array}$ & $2.145,47$ & $4.388,09$ & 104,53 & 11,6 \\
\hline Terra Roxa & $2.530,39$ & $4.136,22$ & 63,46 & 29,3 & Três Barras & $2.341,41$ & $3.596,48$ & 53,6 & 9,1 \\
\hline
\end{tabular}


Eficiência do gasto público na formação do capital humano

\begin{tabular}{|c|c|c|c|c|c|c|c|c|c|}
\hline & & & & & Paraná & & & & \\
\hline $\begin{array}{l}\text { Vera Cruz do } \\
\text { Oeste }\end{array}$ & $2.398,34$ & $4.443,87$ & 85,29 & 29,3 & Anahy & $5.070,39$ & $5.773,06$ & 13,86 & 6,8 \\
\hline Itaipulândia & $7.893,66$ & $10.318,56$ & 30,72 & 28,9 & Quatro Pontes & $3.045,17$ & $5.142,52$ & 68,87 & 6,2 \\
\hline Jesuítas & $2.425,83$ & $4.470,07$ & 84,27 & 28,9 & Céu Azul & $2.991,76$ & $6.188,67$ & 106,86 & 6 \\
\hline Palotina & $2.216,63$ & $3.773,80$ & 70,25 & 28,9 & Diamante do Sul & $2.622,73$ & $5.147,53$ & 96,27 & $-2,3$ \\
\hline \multicolumn{4}{|c|}{ MÉDIA DA EVOLUÇÃO DO IDEB (2005 para 2011) } & 27,1 & \multirow{2}{*}{\multicolumn{3}{|c|}{$\begin{array}{l}\text { MÉDIA DA EVOLUÇÃO IDEB - Brasil (2005 para 2011) } \\
\text { 1) }\end{array}$}} & & 21,1 \\
\hline MÉDIA DA EVC & DOS GASTC & CAPITA DOS & CÍPIOS (2 & $2006-2$ & & & & \multicolumn{2}{|c|}{$74,51 \%$} \\
\hline
\end{tabular}

Fonte: Elaborado pelo autor. 
Partindo da confrontação simples dos resultados, apurados a partir da evolução do gasto per capita/aluno matriculado, pode-se inferir que, na região Oeste do Paraná, os valores destinados à manutenção do Ensino Fundamental - séries iniciais - não estão surtindo os efeitos adequados na qualidade do ensino quando comparados ao IDEB.

Portanto, mesmo utilizando somente estas variáveis para análise, pode-se afirmar que o gasto público em educação não está formando Capital Humano na proporção desejada. Naturalmente pode haver outros fatores que exercem influência no resultado do IDEB, e que nem sempre os recursos são aplicados de forma adequada, porém, é o indicador de qualidade amplamente difundido e que é utilizado como parâmetro para definição e implementação de políticas públicas voltadas à melhoria do ensino no Brasil.

Dessa forma, considerando que há obrigatoriedade na destinação de percentual mínimo de recursos para educação por parte dos municípios, que existem parâmetros pré-definidos que possibilitam o entendimento dos padrões que definem a qualidade do ensino (metas nacionais) e que esta qualidade é medida a partir da nota do IDEB, entende-se ser adequado considerar que quanto maior este índice, maior a formação de Capital Humano.

Considerando que, em relação a 2005, o IDEB 2011 apresentou aumento médio de $27,1 \%$ entre os municípios que compõe a Região Oeste do Paraná, entende-se que houve a formação de Capital Humano, inclusive acima da média nacional que apresentou crescimento de $21,1 \%$, porém com aumento proporcionalmente inferior aos montantes destinados para a educação nestes municípios.

Por outro lado, a qualidade do ensino ou da formação de Capital Humano não pode ficar unicamente atrelada aos recursos financeiros destinados e isto ficou comprovado no Município de Santa Helena onde, com o menor aumento nos gastos per capita com o Ensino Fundamental, 11,3\%, o IDEB teve variação positiva de $32,6 \%$.

Nesse contexto, observando a existência de resultados diversos entre gasto e evolução do IDEB, e após identificar resultado do Coeficiente de Correlação $=-0,0766897$ entre "\% de Evolução do Gasto Per capita entre 2005 e 2006-2011"e a “\% Evolução do IDEB de 2005 
para 2011 ", portanto, não representativo, entendeu-se ser importante identificar o grau de eficiência entre as mesmas variáveis.

Assim, no intuito de ampliar as análises e verificar o grau de eficiência do gasto com educação, sem a intenção de desqualificar os resultados identificados a partir da confrontação entre gasto e IDEB, refletidos na formação do Capital Humano, aplicou-se o método de DEA.

O DEA é um método matemático que utiliza a programação linear para estimar a fronteira eficiente. Para apurar a eficiência pelo método DEA, utilizou-se como Input o "Gasto Médio Per capita entre 20062011 "e como Output a "Evolução do IDEB 2011 em relação a 2005 (\%)" dos 48 municípios, objetos de estudo, da Região Oeste do Paraná.

Conforme demonstrado na Tabela 2, entre os 48 municípios estudados, Santa Terezinha de Itaipu foi o que obteve a maior eficiência, pois houve evolução positiva do IDEB 2011, em relação a 2005, de 70,5\%, a partir de um Gasto Médio per capita/aluno matriculado (20062011 ) de $\mathrm{R} \$ 3.420,26$.

Tabela 2. Eficiência do Gasto Médio Per capita com a Educação entre 2006-2011, considerando a evolução do IDEB 2011 em relação a 2005

\begin{tabular}{|c|c|c|c|c|c|c|c|c|c|}
\hline 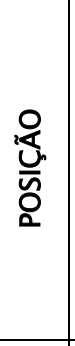 & MUNICÍPIOS & $\begin{array}{c}\text { Gasto } \\
\text { Médio Per } \\
\text { capita } \\
\text { entre } \\
2006- \\
2011 \\
\end{array}$ & $\begin{array}{c}\text { Evoluçã } \\
\text { o do } \\
\text { IDEB } \\
2011 \\
\text { em } \\
\text { relação } \\
\text { a } 2005 \\
\text { (\%) }\end{array}$ & $\begin{array}{c}\text { Eficiênci } \\
a\end{array}$ & 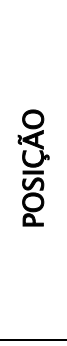 & MUNICÍPIOS & $\begin{array}{c}\text { Gasto Médio } \\
\text { Per capita } \\
\text { entre } 2006- \\
2011 \\
\end{array}$ & 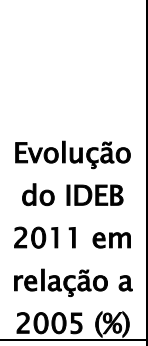 & Eficiência \\
\hline $1^{\circ}$ & Santa T. de Itaipu & $3.420,26$ & 70,5 & 1,00 & $25^{\circ}$ & Iguatu & $6.609,43$ & 33,3 & 0,24 \\
\hline $2^{\circ}$ & Guaíra & $3.526,19$ & 61,8 & 0,85 & $26^{\circ}$ & Braganey & $4.589,85$ & 22,5 & 0,24 \\
\hline $3^{\circ}$ & Foz do Iguaçu & $4.469,20$ & 66,7 & 0,72 & $27^{\circ}$ & Pato Bragado & $5.580,18$ & 21,7 & 0,19 \\
\hline $4^{\circ}$ & Formosa do Oeste & $4.351,15$ & 55,9 & 0,62 & $28^{\circ}$ & $\begin{array}{l}\text { Corbélia } \\
\text { Capitão L. }\end{array}$ & $4.633,23$ & 17,8 & 0,19 \\
\hline $5^{\circ}$ & Nova Aurora & $3.772,59$ & 46,3 & 0,60 & $29^{\circ}$ & Marques & $3.807,89$ & 14,3 & 0,18 \\
\hline $6^{\circ}$ & Cafelândia & $3.497,31$ & 40,4 & 0,56 & $30^{\circ}$ & Santa Helena & $8.738,49$ & 32,6 & 0,18 \\
\hline $7^{\circ}$ & Toledo & $3.093,27$ & 33,3 & 0,52 & $31^{\circ}$ & $\begin{array}{l}\text { Maripá } \\
\text { Boa Vista }\end{array}$ & $4.836,40$ & 18 & 0,18 \\
\hline $8^{\circ}$ & Iracema do Oeste & $4.964,19$ & 51,3 & 0,50 & $32^{\circ}$ & $\begin{array}{l}\text { Aparecida } \\
\text { Diamante Do }\end{array}$ & $3.877,39$ & 14 & 0,18 \\
\hline $9^{\circ}$ & Guaraniaçu & $3.486,00$ & 34,8 & 0,48 & $33^{\circ}$ & $\begin{array}{l}\text { Oeste } \\
\text { Entre Rios do }\end{array}$ & $5.181,56$ & 18 & 0,17 \\
\hline $10^{\circ}$ & $\begin{array}{l}\text { Matelândia } \\
\text { São Pedro do }\end{array}$ & $4.520,55$ & 43,2 & 0,46 & $34^{\circ}$ & Oeste & $6.442,27$ & 22 & 0,17 \\
\hline $11^{\circ}$ & \begin{tabular}{|l} 
Iguaçu \\
Assis
\end{tabular} & $4.518,57$ & 42,1 & 0,45 & $35^{\circ}$ & Campo Bonito & $7.389,62$ & 22,7 & 0,15 \\
\hline $12^{\circ}$ & Chateaubriand & $4.285,23$ & 33,3 & 0,38 & $36^{\circ}$ & | Missal & $5.528,29$ & 16,3 & 0,14 \\
\hline
\end{tabular}




\begin{tabular}{|c|c|c|c|c|c|c|c|c|c|}
\hline $13^{\circ}$ & Palotina & $3.773,80$ & 28,9 & 0,37 & $37^{\circ}$ & $\begin{array}{l}\text { São Miguel } \\
\text { Iguaçu }\end{array}$ & $5.409,32$ & 15,2 & 0,14 \\
\hline $14^{\circ}$ & Mercedes & $4.214,47$ & 31,3 & 0,36 & $38^{\circ}$ & Itaipulândia & $10.318,60$ & 28,9 & 0,14 \\
\hline $15^{\circ}$ & Terra Roxa & $4.136,22$ & 29,3 & 0,34 & $39^{\circ}$ & Santa Lucia & $4.776,47$ & 13,2 & 0,13 \\
\hline $16^{\circ}$ & Ramilândia & $4.497,74$ & 31,4 & 0,34 & $40^{\circ}$ & $\begin{array}{l}\text { Ibema } \\
\text { Santa Tereza }\end{array}$ & $5.101,87$ & 13,6 & 0,13 \\
\hline $17^{\circ}$ & Cascavel & $3.447,04$ & 23,4 & 0,33 & $41^{\circ}$ & $\begin{array}{l}\text { Oeste } \\
\text { Três Barras }\end{array}$ & $4.388,09$ & 11,6 & 0,13 \\
\hline $18^{\circ}$ & Vera Cruz do Oeste & $4.443,87$ & 29,3 & 0,32 & $42^{\circ}$ & Paraná & $3.596,48$ & 9,1 & 0,12 \\
\hline $19^{\circ}$ & $\begin{array}{l}\text { Nova Santa Rosa } \\
\text { Ouro Verde do }\end{array}$ & $4.468,06$ & 29,4 & 0,32 & $43^{\circ}$ & $\begin{array}{l}\text { Tupãssi } \\
\text { São Jose }\end{array}$ & $4.894,33$ & 12,1 & 0,12 \\
\hline $20^{\circ}$ & Oeste & $5.143,97$ & 33,3 & 0,31 & $44^{\circ}$ & Palmeiras & $5.308,48$ & 11,9 & 0,11 \\
\hline $21^{\circ}$ & Jesuítas & $4.470,07$ & 28,9 & 0,31 & $45^{\circ}$ & Quatro Pontes & $5.142,52$ & 6,2 & 0,06 \\
\hline $22^{\circ}$ & Lindoeste & $4.926,85$ & 30,8 & 0,30 & $46^{\circ}$ & Anahy & $5.773,06$ & 6,8 & 0,06 \\
\hline $23^{\circ}$ & Marechal C. Rondon & $3.694,96$ & 19,6 & 0,26 & $47^{\circ}$ & Céu Azul & $6.188,67$ & 6 & 0,05 \\
\hline $24^{\circ}$ & Medianeira & $4.293,53$ & 21,7 & 0,25 & $48^{\circ}$ & Diamante do Sul & $5.147,53$ & $-2,3$ & 0,00 \\
\hline
\end{tabular}

Fonte: Elaborado pelo autor.

O Município de Diamante do Sul apresentou o pior resultado, sendo que, com um Gasto Médio per capita/aluno matriculado de R\$ $5.147,53$, o IDEB, que em 2005 era 4,3, baixou para 4,2 em 2011, uma queda de $2,3 \%$.

Portanto, a identificação da eficiência possibilita criar um ranking entre os municípios, e reafirmar a conclusão anteriormente observada, em que o montante financeiro destinado ao Ensino Fundamental nos municípios do Oeste Paranaense não garante a evolução do IDEB na mesma proporção. Dentre os resultados observados na tabela 2, destaca-se o Município de Itaipulândia, $38^{\circ}$ em eficiência, possui o maior gasto per capita/aluno matriculado, atingindo $28,9 \%$ de evolução no IDEB 2011 em relação a 2005. Se observado somente a evolução do IDEB, ocuparia a posição de número 22 , portanto, uma análise mais detalhada pode alertar para a necessidade de revisar políticas de aplicação dos recursos destinados.

Com base nessa evidência, definiu-se a necessidade de realizar uma segunda parte de análise dos dados, buscando identificar a influência das dimensões que compõem o IDEB e as variáveis que possam impactar no seu resultado, ampliando os elementos disponíveis para possíveis ações corretivas. 


\subsection{Análise das Variáveis que Compõe o IDEB}

O IDEB, representado numa escala de 0 a 10 , é resultado da combinação de duas dimensões: Fluxo Escolar - obtido a partir das taxas de aprovação das escolas; e Desempenho Escolar - obtido a partir da Prova Brasil e SAEB2.

Ao ser instituído pelo Decreto 6094, em abril de 2007, idealizouse uma metodologia que pudesse equilibrar duas dimensões: se houver retenção de alunos visando obter melhores resultados na avaliação da aprendizagem, alcançará resultados ruins na dimensão Fluxo Escolar. Por outro lado, se aprovar todos os alunos, sem ter atingindo o nível adequado de aprendizagem, melhorando o Fluxo Escolar, poderá incorrer em resultados ruins nas avaliações. Os dois casos indicarão necessidade de intervenção e melhoria.

Com base nos resultados do IDEB 2011 , promoveu-se a aplicação de Regressão Múltipla a fim de identificar qual das duas dimensõesFluxo Escolar ou Avaliação-foi determinante para os resultados alcançados. Portanto, tem-se como variável dependente o IDEB e como variáveis explicativas: Fluxo Escolar e Avaliação.

$$
I D E B=-5,22286+0,273953 X_{1}+0,881827 X_{2}+\varepsilon
$$

Onde,

$X_{1}=$ Fluxo Escolar

$X_{2}=$ Avaliação

A partir da aplicação da Regressão Múltipla, com coeficiente de determinação $\mathrm{R}^{2}$ (Ajustado) $=0,99605619$, é possível identificar que a variável $X_{2}$ (Avaliação), com resultado 0,881827 , representou o maior impacto no IDEB/2011, significando que, quanto mais atenção for dada a esta dimensão, melhorando o seu resultado, maior o impacto positivo no resultado do IDEB.

Dessa forma, torna-se importante identificar variáveis que podem influenciar uma possível melhora nos resultados da dimensão Avaliação, a qual exerceu maior impacto nos resultados do IDEB.

A partir de uma ampla análise e coleta de informações, considerou-se as variáveis constantes no Quadro 1 como possíveis influenciadoras da dimensão Avaliação.

\footnotetext{
2 Para maiores informações, consulte <http://inep.gov.br/web/portal-ideb $>$
} 
As variáveis foram coletadas a partir do portal Todos pela Educação (2013) - Taxa de abandono, Meta 3, Média de alunos por turma e Média de horas-aula diária, e do Portal Atlas Brasil (2013) Defasagem Idade Série, Atendimento e Número de pessoas com superior completo. 


\begin{tabular}{|c|c|}
\hline VARIÁVEIS & DETALHAMENTO \\
\hline $\begin{array}{l}\text { Defasagem Idade Série - } \\
\% \text { de } 6 \text { a } 14 \text { anos sem } \\
\text { atraso }\left(X_{1}\right)\end{array}$ & $\begin{array}{l}\text { Razão entre o } \mathrm{n}^{\circ} \text { de pessoas de } 6 \text { a } 14 \text { anos frequentando o } \\
\text { ensino fundamental regular seriado, sem atraso idade- } \\
\text { série, e o } \mathrm{n}^{\circ} \text { total de pessoas nessa faixa etária, } \\
\text { frequentando esse nível de ensino multiplicado por } 100 . \\
\text { Fórmula: [(idade - 5) - número da série frequentada]. } \\
\text { Quanto maior a porcentagem sem atraso, menor o } \\
\text { percentual de retenção, demonstrando não haver seleção } \\
\text { de alunos para realização da Avaliação - Prova Brasil. }\end{array}$ \\
\hline Taxa de abandono $\left(X_{2}\right)$ & $\begin{array}{l}\text { Diferença percentual entre o } \mathrm{n}^{\circ} \text { de matrícula e o } \mathrm{n}^{\circ} \text { de } \\
\text { concluintes do ensino fundamental - séries iniciais. } \\
\text { Quanto menor a taxa de abandono, maior o } \mathrm{n}^{\circ} \text { de alunos } \\
\text { na escola, assim como submetidos à Avaliação - Prova } \\
\text { Brasil. }\end{array}$ \\
\hline $\begin{array}{l}\text { Atendimento }-\% \text { de } 6 \text { a } \\
14 \text { anos na escola }\left(X_{3}\right)\end{array}$ & $\begin{array}{l}\text { Razão entre a população de } 6 \text { a } 14 \text { anos de idade que } \\
\text { estava frequentando a escola, em qualquer nível ou série e } \\
\text { a população total nesta faixa etária multiplicado por } 100 \text {. } \\
\text { Quanto maior a porcentagem de alunos atendidos em } \\
\text { idade adequada ao Ensino Fundamental, mais reais os } \\
\text { resultado da avaliação. }\end{array}$ \\
\hline $\begin{array}{l}\text { Meta } 3 \text { - Todo aluno } \\
\text { com aprendizado } \\
\text { adequado ao seu ano } \\
\left(X_{4}\right)\end{array}$ & $\begin{array}{l}\text { \% dos alunos do Ensino Fundamental - séries iniciais, com } \\
\text { desempenho superior a } 200 \text { pontos na escala de Língua } \\
\text { Portuguesa, e superior a } 225 \text { pontos na escala de } \\
\text { Matemática, do Sistema Nacional de Avaliação da Educação } \\
\text { Básica (Saeb). } \\
\text { Quanto maior o percentual de alunos que tenham atingido } \\
\text { a Meta 3, melhor o resultado no IDEB, na dimensão } \\
\text { avaliação. }\end{array}$ \\
\hline $\begin{array}{l}\text { Número de pessoas com } \\
\text { superior completo }\left(X_{5}\right)\end{array}$ & $\begin{array}{l}\text { Razão entre a população de } 25 \text { anos ou mais de idade que } \\
\text { concluiu pelo menos a graduação do ensino superior e o } \\
\text { total de pessoas nesta faixa etária multiplicado por } 100 \text {. } \\
\text { Quanto maior o número de pessoas com superior } \\
\text { completo, maior o percentual de pais de alunos do Ensino } \\
\text { Fundamental com este nível de ensino, consequentemente, } \\
\text { maior a capacidade de acompanhamento das atividades de } \\
\text { aprendizagem extraclasse. }\end{array}$ \\
\hline $\begin{array}{l}\text { Média de alunos por } \\
\text { turma }\left(X_{6}\right)\end{array}$ & $\begin{array}{l}\text { Razão entre o } \mathrm{n}^{\circ} \text { de alunos matriculados e o } \mathrm{n}^{\circ} \text { de turmas. } \\
\text { Quanto menor a média de alunos por turma, maior a } \\
\text { possibilidade dos professores atenderem individualmente e } \\
\text { auxiliarem nas dificuldades de aprendizagem. }\end{array}$ \\
\hline $\begin{array}{l}\text { Média de horas-aula } \\
\text { diária }\left(X_{7}\right)\end{array}$ & $\begin{array}{l}\text { Razão entre o } \mathrm{n}^{\circ} \text { de horas-aula trabalhadas e o } \mathrm{n}^{\circ} \text { de } \\
\text { turmas. } \\
\text { Quanto maior o número de horas-aula, maior a quantidade } \\
\text { de informações e conteúdos disponibilizados aos alunos, }\end{array}$ \\
\hline
\end{tabular}


consequentemente amplia-se a possibilidade de melhor aprendizagem

Quadro 1: Variáveis que Podem Influenciar a Dimensão Avaliação.

Fonte: Elaborado pelo autor.

Para efeitos da aplicação da Regressão Múltipla, considerou-se como variável dependente a Avaliação e como independente as variáveis que compõe o Quadro 1.

$$
\begin{aligned}
A V A L I A C ̧ \tilde{A} O= & -7,86349+0,173164 X_{1}+0,031539 X_{2}+0,129407 X_{3} \\
& +0,726928 X_{4}+0,058633 X_{5}+0,118118 X_{6}+0,090220 X_{7}+\varepsilon
\end{aligned}
$$

Com base nos resultados da Regressão Múltipla, com coeficiente de determinação $R^{2}$ (Ajustado) =0,62115932, é possível identificar que a variável $X_{4}$ (Meta 3), com resultado 0,726928, representou o maior impacto na dimensão Avaliação, o que significa que, quanto mais atenção for dada a esta variável, melhorando o seu resultado, maior o impacto positivo no resultado da dimensão Avaliação que compõe o IDEB.

A Meta 3 - Todo aluno com aprendizado adequado ao seu ano é uma das cinco metas resultantes do programa "Todos pela Educação", focadas em resultados mensuráveis, que devem ser alcançadas até 7 de setembro de $2022^{3}$.

As cinco metas têm sua importância na formação educacional do provo brasileiro, porém, a Meta 3 refere-se à pretensão de alcançar, até 2022, 70\% ou mais dos alunos com aprendizado adequado ao seu ano. Isso significa que $70 \%$ dos alunos do Ensino Fundamental - séries iniciais - deverão apresentar desempenho superior a 200 pontos na escala de Língua Portuguesa, e superior a 225 pontos na escala de Matemática, na Prova Brasil, médias consideradas adequadas para este nível de ensino.

Portanto, pode-se inferir que, se a dimensão Avaliação exerce maior impacto no resultado do IDEB, a busca em atingir a Meta 3, almejando melhores resultados na Prova Brasil, irá refletir diretamente na melhora do IDEB porque há, nesta meta, a preocupação com as avaliações de Língua Portuguesa e Matemática.

3 Para maiores informações consulte:

http://www.todospelaeducacao.org.br/institucional/as-5-metas/ 
Evidentemente essa conclusão não desqualifica a importância das demais variáveis, somente demonstra que ações e/ou política públicas desenvolvidas na intenção de alcançar a Meta 3 trarão resultados diretos no resultado do IDEB.

\section{CONSIDERAÇÕES FINAIS}

O presente artigo teve como objetivo apurar a eficiência do gasto público com a educação básica - séries iniciais, frente à formação de Capital Humano, na região Oeste do Paraná, a partir da evolução do IDEB, índice que é amplamente difundido e utilizado como parâmetro para implementação de políticas públicas, bem como identificar possíveis variáveis que podem impactar nos resultados deste índice.

A partir da coleta de dados, apurou-se a evolução do gasto com educação dos municípios que compõem a Região Oeste do Paraná, na subfunção que inclui os valores destinados ao Ensino Fundamental séries iniciais, e confrontou-se com a evolução do IDEB.

Os resultados demonstraram que houve um crescimento nos gastos não refletivo nos resultados do IDEB, ou seja, a expectativa de que a destinação de recursos em maior proporção poderia resultar em maior qualidade na educação não foi observada. Embora tenha havido evolução positiva nos resultados do IDEB, essa foi, em proporção, significativamente menor que o crescimento dos gastos, o que, com base na teoria, pode ser interpretado como formação de Capital Humano abaixo do esperado, ou, pelo menos, que os recursos financeiros poderiam ter gerado.

Dada a quantidade de municípios analisados, entendeu-se ser importante identificar a eficiência do gasto com educação frente aos resultados do IDEB. Após a aplicação do método DEA, foi possível visualizar, individualmente, a maior ou menor eficiência na obtenção do resultado do IDEB a partir dos recursos destinados ao Ensino Fundamental - séries iniciais. Os resultados reforçaram o fato de que a análise apoiada somente na destinação do gasto ou no resultado do IDEB não são suficientes para definir intervenções diretas e imediatas ou de políticas públicas voltadas para educação.

Apoiado nessas conclusões, promoveu-se a aplicação da Regressão Múltipla em dois momentos. Primeiro, para identificar qual 
das duas dimensões-Fluxo Escolar ou Avaliação causa maior impacto no IDEB e, segundo, entre um grupo de variáveis pré-definidas, qual deve receber maior atenção na busca de melhores resultados e maior eficiência no gasto público municipal com a educação básica.

Os resultados demonstraram que a dimensão Avaliação causa maior impacto no resultado do IDEB e que esta é fortemente influenciada pela variável Meta 3 - Todo aluno com aprendizado adequado ao seu ano. Dessa forma, entende-se que esta deve receber maior atenção, pois está intimamente ligada aos padrões mínimos a serem atingidos pelos alunos na Prova Brasil que é composta da avaliação de Língua Portuguesa e Matemática.

Dessa forma, conclui-se que, embora os municípios que compõe a Regiões Oeste do Paraná tenham apresentado crescimento no IDEB, este foi proporcionalmente menor quando comparado com os gastos destinados ao Ensino Fundamental - séries iniciais. Esse resultado demonstra que a formação de Capital Humano vem ocorrendo em proporções abaixo do ideal frente aos recursos destinados para este fim.

Para que haja melhora na formação de Capital Humano, ou seja, que os resultados do principal indicador de qualidade, IDEB, apresentem evolução igual ou superior aos gastos com educação, lembrando que este índice é relativamente novo, tendo somente três aferições, portanto, ainda distante do seu limite máximo, do período de estagnação ou acomodação, é importante que sejam desenvolvidas políticas públicas e intervenções no aprendizado dos alunos nas disciplinas de Língua Portuguesa e Matemática, que compõem a dimensão Avaliação do IDEB, uma vez que a dimensão Fluxo Escolar mostrou pouca influência e que esta, mesmo assim, será influenciada positivamente pelo aprendizado.

Das possíveis variáveis que podem influenciar a dimensão Avaliação, conclui-se que a Meta 3, resultante do programa "Todos Pela Educação", deve receber maior atenção com ações e políticas públicas voltadas a atingi-la, com isso, trazendo reflexos diretos no resultado do IDEB e, como consequência, na formação de Capital Humano.

Por fim, é importante ressaltar que outros fatores/variáveis podem influenciar na formação de Capital Humano nas séries iniciais, sobretudo os de caráter mais qualitativo, relacionados às ações diretas 
de professores, gestores, famílias, entre outros, os quais abrem uma nova demanda de estudos, portanto, sugere-se como agenda de pesquisa.

\section{REFERÊNCIAS}

ATLAS BRASIL - Atlas do Desenvolvimento no Brasil 2013. Consulta. Disponível em: <http://www.atlasbrasil.org.br/2013/>Acesso em: 10 out. 2013.

BECKER, G. S. El Capital Humano: um análisis teórico y empírico referido fundamentalmente a la educación. Madrid: Alianza, 1983.

BERCHIELLI, F. O. Investimento em Capital Humano: parâmetro para a determinação de uma política de desenvolvimento econômico. Revista de administração Mackenzie. Ano 1, n.1, 2000, p. 83-101

BRASIL. Constituição (1988). Constituição: República Federativa do Brasil. Brasília, DF: Senado Federal do Brasil, 1988.

BRASIL. Senado Federal. Lei de Diretrizes e Bases da Educação Nacional: nº 9394/96. Brasília : 1996.

COSTA,C. C. R. C. da. O IDEB como Indicador da Qualidade da Educação Brasileira: o caso da região sudeste. E-Xacta, v. 3, n. 2. Belo Horizonte, 2010.

CUNHA, F.; HECKMAN, J.J.; LOCHNER, L.; MASTEROV, D. V.Interpreting the Evidence on Lyfe Cycle Skill Formation. Cambridge, MA, NBER, 2005. Working paper 11331. Disponível em:

$<$ http://www.nber.org/papers/w1 1331.pdf?new_window=1 $>$. Acesso em: 10 nov. 2013.

DELGADO, V. M. S; MACHADO, A. F. Eficiência das Escolas Públicas Estaduais de Minas Gerais. Revista Pesquisa e Planejamento EconômicoPPE. v.37, n.3, 2007. Disponível em: 
<http://www.ppe.ipea.gov.br/index.php/ppe/article/view/1054/1017> . Acesso em: 10 nov. 2013.

DINIZ, C. C.; GONÇALVES, E. Economia do Conhecimento e Desenvolvimento Regionial do Brasil. In: DINIZ, Clélio Campolina. LEMOS, Mauro Borges (Organizadores). Economia e Território. Belo Horizonte: Editora UFMG, 2005.

FRIGOTTO, G. A Produtividade da Escola Improdutiva. Um (re) exame das relações entre educação e estrutura econômico-social capitalista. $4^{\text {a }}$ ed. São Paulo: Cortez, 1993.

GOMES, E. G.; MANGABEIRA, J. A. C. Uso de Análise Envoltória de Dados em Agricultura: o caso de Holambra. Engevista. v. 6, n. 1, p. 19-27, 2004.

HADDAD. P. R. Capitais Intangíveis e Desenvolvimento Regional. Revista de Economia, v. 35, n. 3 (ano 33), p. 119-146, set./dez. 2009. Editora UFPR

HECKMAN, J. J. The Real Question is How to Use the Available Funds Wisely. The Best Evidence Supports the Policy Prescription: Invest in the Very Young. 2000 Disponível em:

$<$ http://www.ounceofprevention.org/news/pdfs/heckmaninvestinveryyo ung.pdf $>$ Acesso em: 13 nov. 2013.

INEP - Instituto Nacional de Estudos e Pesquisas Educacionais Anísio Teixeira. $O$ que é $o$ ldeb. Disponível em: < http://portal.inep.gov.br/web/portal-ideb/o-que-e-o-ideb> Acesso em: 01 nov. $2013 \mathrm{a}$.

INEP - Instituto Nacional de Estudos e Pesquisas Educacionais Anísio Teixeira. IDEB - Resultados e Metas. Disponível em:

$<$ http://ideb.inep.gov.br/resultado/resultado/resultado.seam?cid=2594 84> Acesso em: 17 de out. $2013 \mathrm{~b}$.

INEP - Instituto Nacional de Estudos e Pesquisas Educacionais Anísio Teixeira. Sistema de Consulta a Matrícula do Censo Escolar. Disponível 
em: $\quad<$ http://portal.inep.gov.br/basica-censo-escolar-matricula $>$. Acesso em: 17 out. $2013 c$.

MEDEIROS, José Adelino de Souza. Alcance e limitações da teoria do capital humano: diferenças de ganhos no Brasil em 1973. São Paulo: IPE/USP, 1982.

MOG - Ministério do Orçamento e Gestão. Portaria $n^{\circ} 42$, de 14 de abril de 1999. Atualiza a discriminação da despesa por funções de que tratam o inciso I, do $\S 1^{\circ}$, do art. $2^{\circ}$, e $\S 2^{\circ}$, do art. $8^{\circ}$, ambos da Lei $n^{\circ}$ 4.320, de 17 de março de 1964; estabelece conceitos de função, subfunção, programa, projeto, atividade, operações especiais e dá outras providências. Diário Oficial da União, Brasília, DF, 15 abril 1999.

NERI, M. Educação da Primeira Infância. Conjuntura Econômica, Rio de Janeiro, dez. 2005. Temas Sociais, p. 30-32.

REIS, D. A importância do Ensino Fundamental: ter uma excelente formação nos quatro primeiros anos da escola garante à criança melhor desempenho na universidade. 2012. Disponível em:

$<$ http://educarparacrescer.abril.com.br/aprendizagem/importanciaensino-fundamental-683592.shtml> Acesso em: 10 nov. 2013.

SAUL, R. P. As Raízes Renegadas da Teoria do Capital Humano. Sociologias, Porto Alegre, ano 6, $\mathrm{n}^{\circ}$ 12, jul/dez 2004, p. 230-273.

SCHULTZ, T. W. Investindo no Povo: o segredo econômico da qualidade da população. Rio de Janeiro, Forense: 1987.

SCHULTZ, T. W. O Capital Humano. Rio de Janeiro: Zahar, 1973.

SCHULTZ, T. W. O Valor Econômico da Educação. Rio de Janeiro: Zahar, 1967.

SIEDENBERG,D. R. (Org.). Desenvolvimento sob Múltiplos Olhares. 1 ed. ljuí / RS: Editora Unijuí, 2012, v. 1, p. 10-62. 
SISTN - Sistema de Coleta de Dados Contábeis de Estados e Municípios. Quadro de Dados Contábeis Consolidados Municipais do Balanço Orçamentário. Disponível em:

$<$ http://www3.tesouro.fazenda.gov.br/estados_municipios/sistn.asp $>$. Acesso em: 16 out. 2013.

TODOS PELA EDUCAÇÃO. Busca Comparativa.

Disponível em: <http://www.todospelaeducacao.org.br/educacao-nobrasil/buscacomparativa/>Acesso em: 13 out. 2013.

VIANA, G; LIMA, J. F. de. Capital humano e crescimento econômico. Interações, Campo Grande, v. 11, n. 2 p. 137-148, jul./dez. 2010.

Submetido em: 14/05/2014.

Aprovado em: 14/10/2015.

\section{Sobre o autor}

Martin Airton Wissmann

Doutorando em Desenvolvimento Regional e Agronegócio-PGDRA - Unioeste. Professor da Universidade Estadual do Oeste do Paraná - UNIOESTE.

Endereço: Rua São Luiz, 1181 - Novo Sarandi. 85.927.000 - Toledo, PR, Brasil.

E-mail:martinairton@gmail.com 